\title{
Modelling Short-run Money Demand for the US
}

\author{
Marcus Scheiblecker \\ Correspondence: Marcus Scheiblecker, Austrian Institute of Economic Research, Austria.
}

\author{
Received: June 29, $2017 \quad$ Accepted: July 27, $2017 \quad$ Available online: August 3, 2017 \\ doi:10.11114/aef.v4i5.2575 URL: https://doi.org/10.11114/aef.v4i5.2575
}

\begin{abstract}
There is a vast amount of empirical evidence concerning the cointegrating relationship between money demand, some kind of interest rate and income. In contrast to this, short-run dynamics are still opaque. In the existing literature, the return to steady state is modeled quite differently. The range goes from simple error correction models to non-linear approaches.

We herewith propose a method for considering not only disequilibria between money demand and its steady state for the last period only, but also for such of the recent past in a parsimonious and economically meaningful way. As different from multicointegration, weights for cumulating steady-state deviations are geometrically decreasing, the more they are located in the past. This model possesses an ARMA $(1,1)$ representation and leads to an ARMAX-model, if combined with a conventional error correction model. This approach is shown to track money demand short-run dynamics better and more parsimoniously than partial-adjustment models.
\end{abstract}

Keywords: short-run money demand, cumulative error-correction model

\section{Introduction}

Nowadays, modeling long-term money demand is largely straightforward. There is a vast amount of empirical evidence concerning the existence of a cointegrating relationship between real money demand, some kind of interest rate and income. Examples for the US are Hoffman and Rasche (1991) or Stock and Watson (1993), for the UK Ericsson, Hendry and Prestwich (1998) and Teräsvirta and Eliasson (2001), or for the euro area Calza and Zaghini (2006) or Dreger and Wolters (2010).

In contrast to this, the short-run dynamics is still opaque. Theoretically, the existence of portfolio adjustment costs is frequently used to explain the sluggish return to steady state. In this case, the money amount held by the economic agent acts as a "buffer stock" (Laidler, 1984) for smoothing the differences between income and expenditure streams. In the empirical literature, there are many different approaches to modeling the inertia of the adjustment process back towards the long-run relation. Goldfeld (1973) applied a so-called partial adjustment model by including a lagged dependent variable to model the inertia of return. With the upcoming popularity of error correction models, Baba, Hendry and Starr (1992) and Duca (2000) are prominent examples for attempts to model short-run dynamics in money demand. Since simple error correction models in some casesdid not produce satisfying statistical results, several authors applied non-linear versions. Hendry and Ericsson (1991) and Escribano (2004) tested a cubic polynomial error correction model. Examples for regime-dependent adjustment dynamics are Lütkepohl, Täresvirta and Wolters (1999) or Teräsvirta and Eliasson (2001).

\subsection{The Problem}

The reason for the large amount of different approaches towards modeling the return to steady-state may be that the disequilibrium - which has to be balanced by economic agents - is not defined correctly. All these models consider the disequilibrium to be balanced by short-run dynamics as the gap between money demand and its steady state for the last period only, disregarding disequilibria in earlier periods. But there seems to be no convincing argument why agents should balance only the disequilibrium of the most recent period. This goes especially for cases of higher-frequency (daily, weekly, monthly or quarterly) data. Ignoring deviations from steady state that occurred further back in the past fail to account for money stockpiling by economic agents. Positive deviations from steady state of past periods may be cumulated [?] and used for transaction or saving purposes in the current period without making it necessary to balance the deviation of the most recent past. These cumulated deviations from steady state of the past form a further variable which, if not considered, could lead to mis-specification of the model. 


\subsection{Objective of the Study}

We herewith present a model that accounts not only for the most recent deviation from the long-run relation in the short-run adjustment process, but also for disequilibria that occurred further back in the past. With this type of model we need no assumptions concerning sluggish adjustment due to adjustment costs. Only the fact that deviations from steady state located earlier than in the most recent period may be relevant. The outline of the paper is as follows. Section 2 presents the so-called cumulative error correction model. In Section 3 this model is applied to the dataset used by Ball (2012) where the same long-run relationship is used and just short-run dynamics compared. Section 4 concludes.

\section{Method}

The idea of accounting also for disequilibria further in the past than in the most recent period within the framework of error correction models (ECM) is not new. Granger and Lee (1989) presented a model where all past deviations from steady state are summed up with equal weights until the starting period of the time series. In their example, the mismatch between production and sales for any lag leads to the accumulation of inventories. In such a situation, the application of a standard ECM would result in a specification error ${ }^{1}$. Apart from the cointegrating relationship between the flows (first-level cointegration), there may be another one from stock levels which the authors called second-level cointegration. This new series emerging from the accumulation of past disequilibria form a further cointegrating relationship called multicointegration. Whereas usually the number of cointegrating relationships among $\mathrm{n}$ variables is at most $\mathrm{n}-1$, it can be $\mathrm{n}$ as well within this framework. A drawback of this approach is that the second-level cointegrating relationship contains I(2) variables, constructed by the summation of I(1) flow variables, which complicates the estimation process.

Suppose that $\mathrm{y}_{\mathrm{t}}$ and $\mathrm{x}_{\mathrm{t}}$ are both $\mathrm{I}(1)$ and are cointegrated $\mathrm{CI}(1,1)$ so that

$$
z_{t}=y_{t}-\phi x_{t}
$$

is $\mathrm{I}(0)$. (1) defines the so-called first-level cointegration relationship. Granger and Lee (1989) propose to sum up all past deviations from steady state with the same weight 1 to a new stock variable $s_{t}=\Sigma z_{t}$. If now $s_{t}$ cointegrates with either $\Sigma \mathrm{x}_{\mathrm{t}}$ or $\Sigma \mathrm{y}_{\mathrm{t}}$ we get another cointegration relationship (second-level cointegration) so that $\mathrm{s}_{\mathrm{t}}-\kappa \mathrm{y}_{\mathrm{t}}$ again forms a stationary relationship

$$
s_{t}-\kappa y_{t}=\sum_{j=1}^{t} y_{t}-\phi \sum_{j=1}^{t} x_{t}-\kappa y_{t}
$$

with $\mathrm{s}_{\mathrm{t}}$ being I(1) and $\Sigma \mathrm{y}_{\mathrm{t}}$ and $\Sigma \mathrm{x}_{\mathrm{t}}$ being I(2) as both are summed I(1) variables. ${ }^{2}$ Granger and Lee (1989) solved the estimation problem by a two-step method as typically used for $\mathrm{CI}(1,1)$ variables. In a first step, they estimated the first-level cointegration relation. The residuals representing deviations from steady state were summed up and, in a second stage, regressed on the cumulated variables (summed $y_{t}$ ) for estimating the second-order cointegrating relationship.

Engsted et al. (1997) have shown that in case of a two-step method, the first cointegrating relationship (of flows) must not be estimated, but derived by another method. Otherwise the test statistics of the second one will have a different limiting distribution compared with normal settings. Furthermore, for I(2)-based models usual asymptotic $\chi^{2}$ inference is invalid and Johansen (2006) pointed out that it can be used only if a multicointegration relation is assumed with properties hardly met in reality.

\subsection{The Cumulative Error Correction Model}

The model presented here instead, uses weights for cumulation which are geometrically decreasing the more the disequilibria are located in the past. According to Koyck (1954), such models possess an ARMA $(1,1)$ representation. The combination of the Koyck-model with the error correction approach leads to an ARMAX model which is shown to be in some cases capable to track money demand short-run dynamics better and more parsimoniously than partial-adjustment models. Probably, even adjustment structures modeled by non-linear ECM can be explained better

\footnotetext{
${ }^{1}$ See for this Engsted and Johansen (1997) or Lee (1992)

${ }^{2}$ In the case of multicointegration, the corresponding ECM considers adjustment mechanisms for the stock as well as
}

the flow variables with $\Delta x_{t}=c+\alpha_{1}\left(s_{t-1}-\kappa y_{t-1}\right)+\alpha_{2} \xi_{t-1}+$ lagged $\left(\Delta x_{t}, \Delta y_{t}\right)+u_{t}$ 
by this model type.

This model has recently been put forward by Scheiblecker (2013) for the empirical application of modeling private consumption in the US.

The typical ECM

$$
\Delta y_{t}=\alpha \xi_{t-1}+\gamma \Delta x_{t}+c+u_{t}
$$

with $y_{t}$ and $x_{t}$ being observed flow variables, $c$ a scaling factor, $u_{t}$ an iid error term and $\xi_{t-1}=y_{t-1}-y_{t-1}^{*}$ which measures the distance between the steady state $y^{*}$ and the time series $y$ one period ago. As usual, the EC parameter $(0>\alpha>-1)$ partly settles deviations occurred at time $\mathrm{t}-1$ in $\mathrm{t}$.

Based on considerations that deviations located further in the past than $\mathrm{t}-1$ could influence current balancing activities, a transformation of (3) in

$$
\Delta y_{t}=\beta \sum_{i=0}^{\infty} \lambda^{i} \xi_{t-1-i}+\gamma \Delta x_{t}+c+u_{t}
$$

with the weight $\lambda<1$, is proposed.

Koyck (1954) was the first one to put forward the transformation of an ADL model of the type

$$
F_{t}=c+\delta \sum_{j=0}^{\infty} \lambda^{j} S_{t-j}+\varepsilon_{t}
$$

into an $\operatorname{ARMAX}(1,1)$ model

$$
F_{t}=(1-\lambda) c+\delta \lambda^{0} S_{t-0}+\lambda F_{t-1}+\varepsilon_{t}-\lambda \varepsilon_{t-1}
$$

where $\lambda F_{t-1}$ represents the autoregressive [AR] part, $-\lambda \varepsilon_{t-1}$ the moving average [MA] part and $S_{t}$ the exogenous regressor, which is therefore called the Koyck model. The summing weights $\lambda$ (called the retention rate) are defined over $0 \leq \lambda \leq 1$ such that their size is decreasing geometrically giving less weight to more distant observations.

If we replace $S_{t-i}$ in equation (5) and (6) for $\xi_{t-i-l}$ (so that $S_{t}=\xi_{t-l}$ ), $F_{t}$ corresponds to the right hand side of equation (4) 3 $^{3}$. So (4) can be transformed into

$$
\Delta y_{t}=(1-\lambda) c+\beta \xi_{t-1}+\lambda \Delta y_{t-1}+\gamma \Delta x_{t}-\lambda \varepsilon_{t-1}+\varepsilon_{t}
$$

which is the ARMAX representation of our cumulative ECM given in (5). It is straightforward that as long as $\lambda<1$ all terms on either side of the equation are $\mathrm{I}(0)$ and hence the usual test statistics can be applied in order to determine the cointegrating relationship.

This approach is very parsimonious as only one parameter more (the retention parameter $\lambda$ ) than in the conventional ECM has to be estimated. It is also noteworthy that if the parameter $\delta$ in (6) is zero (i. e. no cointegration exists between the two series) the retention parameter $\lambda$ can not be retrieved from the model. On the other side, if $\lambda$ is zero we obtain the conventional ECM, and if it is 1 we arrive at the multicointegration method with equal weights as proposed by Granger and Lee (1989). ${ }^{4}$

\subsection{Economic Interpretation of the Cumulative Error Correction Model}

This time series representation of an ECM attenuates somewhat the reproach against ARIMA models for their lack of theoretical content. This form seems to be based on economic theory no less than the conventional ECMs and the multicointegration method, as the retention rate $\lambda$ is located between both approaches. Equation (7) is an ARMAX model type that implicitly includes I(1) variables in levels - as represented by their I(0) deviations from steady state as well as an AR and a MA term. The only difference to a typical ARMAX model is that (7) requires the AR parameter to equal the MA one with different signs and that both terms are restricted to be of order one.

\footnotetext{
${ }^{3}$ Disregarding for a moment the regressor $\Delta x_{t}$.

${ }^{4}$ In this case the specification of the model is not exactly correct because the second-level cointegrating relationship is not considered explicitly here.
} 
Scheiblecker (2013) has shown that this type of model has interesting features concerning its stability, defined as the situation where a time series is only driven by its exogenous short-term variables $(\Delta x t)$ and the error term $(\varepsilon t)$. For the conventional ECM this is the case if the error of the past period was zero. For the cumulated ECM it is the case if the weighted sum of disequilibria of the past is zero. Such a situation can even occur outside steady state, at least for a short time.

\section{Modeling US Short-run Money Demand}

\subsection{The Theory of Short-run Money Demand}

Ericsson, Hendry and Prestwich (1998) developed the notion that one of the reasons for the demand for money is to act as an inventory in order to smooth differences between income and expenditure streams. If this is true, it makes sense to account not just for the inventory of money resulting from the disequilibrium of the most recent past but also from earlier periods. For this reason, a cumulated ECM (cumECM) makes sense and serves to model the short run money demand for the US.

As referred to in the introduction, modeling short-run movements around the long-run path of money demand is not straightforward. Many economists have tried to model this relation by very different models. As the intention of this paper is not to challenge the existence or structure of possible long-run relationships, but just to concentrate on the short-run dynamics, I use the same data set as well as the same steady-state parameters as published by Ball (2012).

\subsection{Alternative Models}

According to Ball (2012), the assumption of opportunity costs is necessary to explain the sluggish, arbitrarily chosen AR(2) adjustment in a partial-adjustment model. While we use the same interest rate here, the inertia does not stem from opportunity costs of adjustment, but from stockpiling of past periods. From a theoretical point of view, this difference is important as sluggish behavior due to adjustment costs is a different motivation than rapid reaction triggered by some disregarded stock variable.

Based on this, following Stock and Watson (1993), Ball (2012) estimated for the US a semi-logarithmic long-run money demand function of the form

$$
m-p=\alpha+\theta_{y} y+\theta_{R} R+\varepsilon
$$

where price homogeneity is assumed to be valid in the long-run. $m$ represents the logarithm of M1, $p$ the logarithm of the GDP deflator, $y$ the log of real US-GDP, $R$ is the interest rate of "near money" and $\varepsilon$ the error term showing deviations from steady state. Ball (2012) estimated the cointegrating relationship by Dynamic OLS as introduced by Stock and Watson (1993), obtaining a long-run income elasticity $\theta_{y}$ of 0.47 and an interest rate semi-elasticity $\theta_{R}$ of -0.082 .

In order to model the short-run dynamics around the steady state, the author used a partial adjustment model where desired money holdings deviate from the steady state value $\left(m^{*}\right)$ and are represented by $m^{*}+\eta$ with $\eta$ being a shock that is assumed to follow an $\operatorname{AR}(2)$ process. The reasoning behind this is that the adjustment of money stock is costly and therefore takes place only gradually towards the desired equilibrium, following an AR(2) process.

Ball (2012) has furthermore shown that his approach possesses an ECM representation of the form

$$
\begin{aligned}
\Delta m= & k\left(1-\rho_{1}-\rho_{2}\right)+\mu\left(1-\rho_{1}-\rho_{2}\right)\left(m *_{-1}-m_{-1}\right) \\
& +\left(\rho_{1}-\mu \rho_{1}-\mu \rho_{2}\right) \Delta m_{-1}+(1-\mu) \rho_{2} \Delta m_{-2} \\
& +\mu \Delta m *+\mu \rho_{2} \Delta m *_{-1}+\mu v
\end{aligned}
$$

with restrictions to the parameters used as compared with a conventional ECM. In this formula, $k$ is a scaling parameter, $\mu$ the speed of adjustment of money holdings, $\rho_{1}$ and $\rho_{2}$ the two parameters of the $\operatorname{AR}(2)$ process determining the development of $\eta$ over time and $v$ an iid error term. $\left(m_{-1}{ }_{-1}-m_{-1}\right)$ is the traditional EC-term which only considers the deviation from steady state in the most recent past (period t-1). This ECM is supplemented with an AR(2) process in order to capture residual auto-correlation stemming from sluggish adjustment.

Contrary to the partial adjustment model which is an AR(2) model, the proposed cumulative ECM is an ARMA $(1,1)$ model with the restriction that the AR and the MA term are of the same size, but with different signs. As a MA(1) possesses an $\operatorname{AR}(\infty)$ representation, the cumulative ECM is capable of capturing higher autoregressive dynamics than AR(2). In order to quantify (9), six parameters have to be estimated to model short-run dynamics of this kind. 


\subsection{The Data}

For the sake of comparison, we use the same data as in Ball (2012). The Appendix presents these data on a quarterly frequency between IIQ1959 and IVQ1993. Income is represented by real GDP (chain linked in US-Dollars) downloaded from the Federal Reserve Data Base (FRED) in May 6, 2013. M1and the GDP deflator (representing prices) also originate from this data base. Instead of using the Treasury Bill rate or a commercial paper rate as a proxy for the short-term market interest rate like in many other studies, Ball (2012) constructed an average return rate of "near monies" which is used in our model as well, as shown in the table. This interest rate for "near money" should better reflect the opportunity cost of holding money than other short-term interest rates. It includes interest rates for all non-M1 components of M2, except time deposits. This synthetic interest rate represents a weighted average of interest rates for saving accounts with zero maturity, retail money market mutual funds and money market deposit accounts.

Figure 1 gives the logs of M1 as well as its steady state as represented by (8). Differences between both lines represent the deviations from the steady state which are used to set up ECMs.

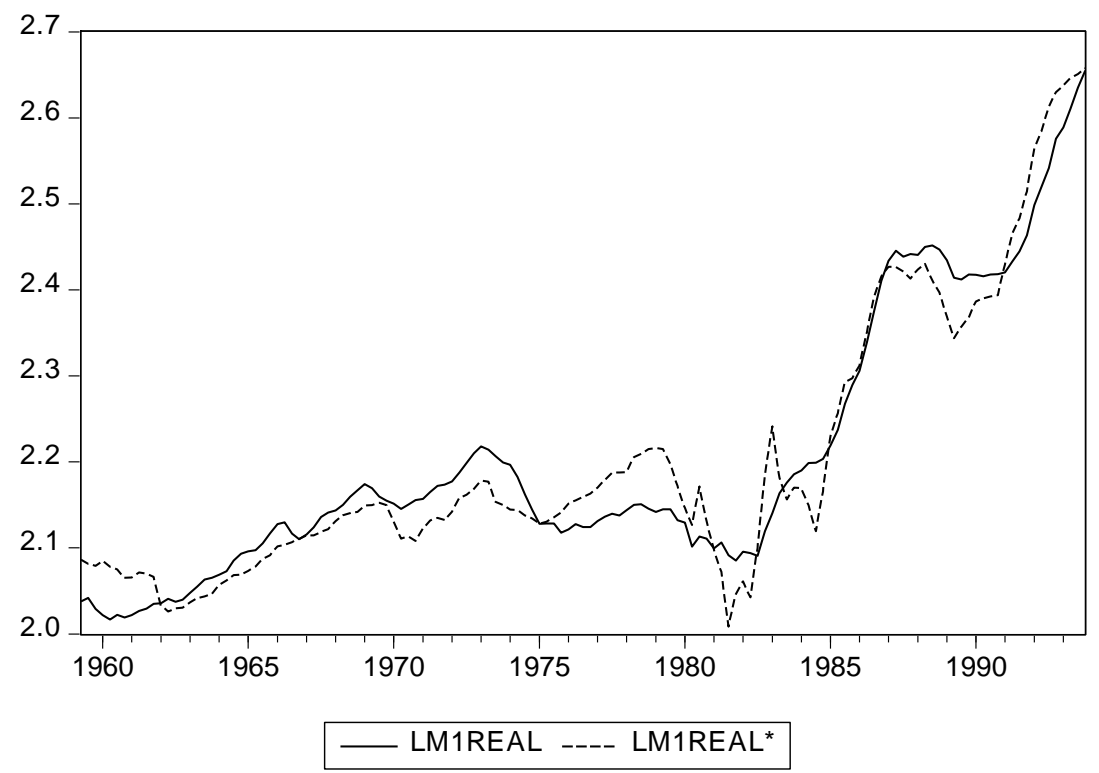

Figure 1. Headline and steady state demand for M1

Source: FRED retr. May 6, 2013, Ball (2012)

\subsection{Application of the Cumulative Error Correction Model}

The cumulative ECM used here for estimating short-term movements of US money demand between 1960 and 1993 on a quarterly basis is

$$
\Delta m_{t}=(1-\lambda) c+\beta \xi_{t-1}+\lambda_{A R} \Delta m_{t-1}-\lambda_{M A} \varepsilon_{t-1}+\gamma_{y} \Delta Y_{t}+\gamma_{R} \Delta R_{t}+\varepsilon_{t}
$$

or explicitly respecting the restriction of $\lambda_{A R}=-\lambda_{M A}$

$$
\Delta m_{t}=(1-\lambda) c+\beta \xi_{t-1}+\lambda\left(\Delta m_{t-1}-\varepsilon_{t-1}\right)+\gamma_{y} \Delta Y_{t}+\gamma_{R} \Delta R_{t}+\varepsilon_{t}
$$

with $m_{t}$ being the log of real M1, (1- $\left.\lambda\right) \mathrm{c}$ a constant scaling parameter, $\xi_{\mathrm{t}-1}$ the deviation of real M1 from its steady state as estimated by Ball (2012), $Y$ the log of real GDP and $R$ the interest of near money.

According to this approach, five parameters have to be estimated: the constant (if necessary at all), the EC parameter $\beta$, the retention rate $\lambda$, the income elasticity $\gamma_{y}$ and the interest semi-elasticity $\gamma_{R}$. As shown in (7) the retention rate appears twice in (10).: once as an AR-parameter $\left(\lambda_{A R}\right)$, and the second time with the same value, but with a different sign as the MA-parameter $\left(-\lambda_{M A}\right)$.

\subsection{Results}

For estimation in practice, there are two possibilities: either to restrict the parameters to be equal with different signs $\left(\lambda_{A R}=-\lambda_{M A}\right)$ as given in (11), or to estimate them independently, like proposed in (10). The first approach has the advantage of one parameter being saved, but at the cost of a more complicated estimation procedure. Fransens and van Oest (2007) have shown that such a restriction requires maximum likelihood estimation and errors are non-normally 
distributed because of the so-called Davies (1987) problem. They propose several alternative test statistics, of which we use here the average absolute t-statistics in order to test the significance of the estimated parameters.

On the other hand, estimating both parameters independently allows verification of whether they have the same absolute value (irrespective of the sign) and hence the appropriateness of assuming geometrically decreasing weights. We follow both approaches here, and the results are given in Table 1.

Table 1. Parameters of the short-run Money Demand

\begin{tabular}{lcr}
\hline & Unrestricted & Restricted $^{5}$ \\
\hline $\boldsymbol{\beta}$ & $-0.024 * * *$ & $-0.016 * * *$ \\
$\lambda_{\mathrm{AR}}$ & $0.701 * * *$ & $0.701 * * *$ \\
$\lambda_{\mathrm{MA}}$ & $-0.431 * * *$ & $-0.701 * * *$ \\
$\gamma_{\mathbf{y}}$ & $0.167 * * *$ & $0.165 * * *$ \\
$\gamma_{\mathbf{R}}$ & $-0.018 * * *$ & $-0.019 * * *$ \\
\hline
\end{tabular}

$* * *=$ significant at a $1 \%$ confidence level

All estimated parameters have been found to be highly significant. Furthermore, in none of the approaches an outlier in 1980q3 considered by a dummy variable - as found by Ball (2012) - turned out to be significant. The EC parameter $\beta$ is somewhat higher with -0.024 in the unrestricted case than in the restricted $(-0.016)$. From (9) one can derive Ball's EC-parameter of $t-1$ with a value of 0.05 that is higher than in the cumECM case. The short-term income elasticity and the interest semi-elasticity are practically the same in both approaches. According to these, a one- percent rise in income in the US leads to a higher demand for real M1 of around 0.167 percent. A one-percentage- point higher interest rate for near monies leads to a reduction of real M1 of 0.018 percent.

In the unrestricted approach, the AR parameter $\lambda_{A R}$ and the MA parameter $\lambda_{M A}$ are quite different, apart from their sign. Unfortunately, the $5 \%$ confidence intervals did not overlap, hence the Wald-test for the equality of parameters failed. This inconsistency hints at a retention rate that does not decrease according to a geometric pattern, but in some other, e. g. triangular form. Interestingly, the restricted model supports a retention rate of the same magnitude as the unrestricted AR parameter. Usually, in this case the restricted form shows a parameter located somewhere in the middle between the unrestricted AR and MA parameter (see e. g. Scheiblecker, 2013). Nevertheless, the restricted retention rate turned out to be highly significant. Figure 1 shows the decrease over time of the weights given to past deviations from steady state with a retention rate of 0.70 .

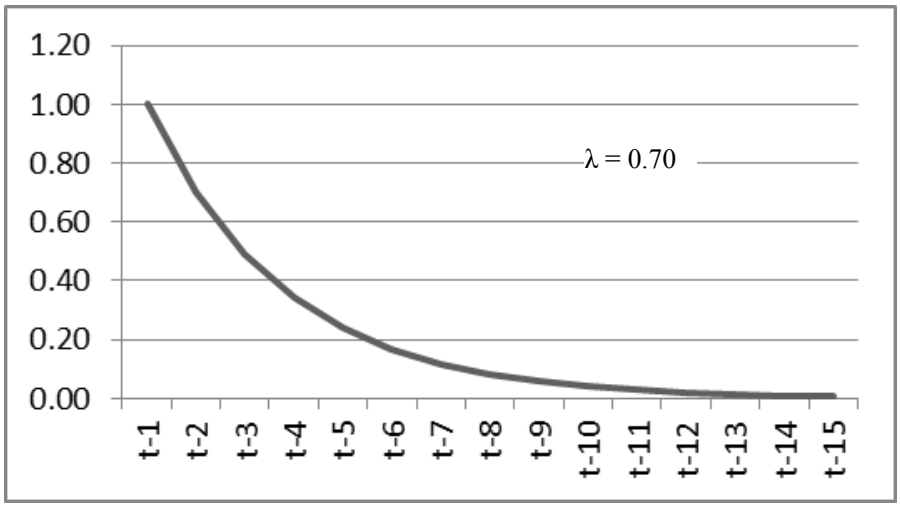

Figure 2. Retention rate over periods

In the first period $\mathrm{t}-1$, the retention rate $\lambda$ is one $\left(\lambda^{0}\right)$ so that the attraction toward steady state is fully determined by the EC parameter $\beta$ like in conventional ECMs. In the period before (t-2), the retention rate reduces the weight of the EC parameter by the factor 0.7 and so on. In the current period, deviations from steady state that occurred 8 quarters in the past still have a weight of around 0.10. After 14 quarters, the effect has completely faded out and disequilibria before that time do not influence short-term movements of money demand in the current period.

The Jarque-Bera statistics concerning the residuals of the restricted and the unrestricted model yielded a value of 1.281

${ }^{5}$ Critical values for testing $\beta=0$ are taken from Fransens and van Oest (2007) Table 2 page 294. For a sample size of 1000 , the critical value of a $95 \%$ confidence level is 1.80 . 
(probability: $0.527 \%$ ) or 0.730 (probability: $0.694 \%$ ), respectively. So their normality in distribution could not be rejected by far. Furthermore, no auto-correlation in the residuals was found.

\subsection{Comparison with Other Model Results and Discussion}

It is difficult to compare the results with those of Ball (2012), as different parameters had been estimated there. Furthermore, the author did not report many test statistics apart from those concerning the single parameters. In order to compare the quality of the models, I use several information criteria as suggested in the literature for discrimination between alternative models. As no values for such criteria are given in Ball (2012), his model had to be re-estimated for calculating three information criteria: the Akaike information criteria, the Schwarz criterion and the Hannan-Quinn criterion. Table 2 shows the respective results.

Table 2. Information criteria

\begin{tabular}{|c|c|c|c|}
\hline & $\begin{array}{ll}\text { partial adjustment } \\
\text { model }\end{array}$ & $\begin{array}{l}\text { cumECM } \\
\text { unrestricted }\end{array}$ & CumECM restricted \\
\hline Akaike & -7.089652 & -7.100734 & -6.260050 \\
\hline Schwarz & -6.939736 & -6.972852 & -6.153482 \\
\hline Hannan-Quinn & -7.028730 & -7.048766 & -6.216744 \\
\hline
\end{tabular}

Since all three criteria show lower values for the unrestricted cumulative ECM than for the partial adjustment model, the unrestricted version should be the preferred one. However, the restricted version could not outperform the partial adjustment model as all its values are higher.

Above, it has been shown that the cumulative ECM nests the multi-cointegration model and the conventional ECM. As the partial adjustment model of Ball (2012) includes an AR(2) process and the cumulative ECM with its ARMA $(1,1)$ process auto-regressive elements of any lag order, it is not astonishing that both models show roughly similar residuals in the underlying case. The partial adjustment model of Ball (2012) cuts-off influences from deviations from steady state located more than three periods in the past. This is not the case with the cumulative ECM, but the weights for those lags are decreasing rapidly, especially for low retention rates. Figure 2 shows the similarity of residuals of the partial adjustment model in the upper part, the restricted ECM in the middle and the unrestricted in the lower part of the graph. ${ }^{6}$ Nevertheless, the theoretical reasoning behind both approaches is quite different, and in other cases, the missing variable in the partial adjustment model could make for a larger difference between he two methods.



Figure 3. Residuals

\section{Conclusions}

It could be shown, that the proposed cumulative error correction model has several interesting properties like a meaningful economic interpretation and a robust and parsimonious model specification.

\subsection{Model Properties}

As different from the conventional ECM, the cumulative ECM accounts not only for the most recent deviation from the steady state, but also for those located further in the past, thereby allowing for some kind of stockpiling. For most economic problems, the inclusion of such activities is more adequate for modeling the behavior of economic agents.

Unlike the multi-cointegration model as proposed by Granger and Lee (1989), where all past deviations are assigned equal weights back to the start of the time series, we assume (and test) geometrically decreasing weights and estimate the related retention rate - which captures the size of the weights as well as their fading over time -from the data. This

${ }^{6}$ The residuals have been shifted with a constant term, for better comparison in the graph. 
leads to a more parsimonious and easier-to-estimate specification over a broad range of applications.

A strong property of the cumulative version is that the common ECM is completely nested as the retention rate can even be zero. On the other hand, if the retention rate is one, the multi-cointegration model emerges, but in this case the cumulative ECM will not be correctly specified as it does not explicitly allow for the second-level cointegrating relationship. Likewise, the partial adjustment model is nested as the cumECM covers auto-regressive movements of any lag order, due to its ARMA $(1,1)$ representation.

Estimated conventional ECMs sometimes suffer from autocorrelation in the residuals. For practical purposes, this is often dealth with by including AR-terms. Sometimes this is done without any theoretical justification; in other instances - like in the case of the partial adjustment model - the reasoning is based on opportunity costs leading to sluggish adjustment. In the case of the cumECM, such assumptions are not necessary since the inclusion of an ARMA process is based only on theoretical grounds whereby disequilibria of past periods may also matter.

\subsection{Economic Findings}

The results of the applied cumECM show that stockpiling activities in past quarters contribute to considerable extent to the explanation of demand for M1 money. For the US a retention rate of 0.7 indicates that deviations from steady state demand of the past 2 years (8 quarters) play a significant role for short-term demand. On the other side, the classical EC parameter - reflecting the reaction to the steady state deviation in the most recent period -shows a lower value than in other studies, i.e. only half the size as in a comparable study by Ball (2012).

In order to interpret the most recent money demand changes correctly, economic policy should give greater consideration to stockpiling behavior in the past. The zero lower bound environment following the Great Recession of the years 2007/2008 has changed substantially the dynamics of money demand.. In this regard, there is strong need for further research.

\section{Acknowledgements}

The author is indebted to Prof. Laurence M. Ball from Johns Hopkins University for providing his data set.

\section{Appendix}

$\begin{array}{lcccc}\text { Date } & \text { r_star } & \text { Yr } & \text { Py } & \text { M1 } \\ \text { 1959 Apr } & 2.36 & 2776.4 & 18.314 & 140.533 \\ \text { 1959 Jul } & 2.41 & 2773.1 & 18.366 & 141.533 \\ \text { 1959 Oct } & 2.46 & 2782.8 & 18.443 & 140.300 \\ \text { 1960 Jan } & 2.51 & 2845.3 & 18.521 & 139.900 \\ \text { 1960 Apr } & 2.57 & 2832.0 & 18.579 & 139.600 \\ \text { 1960 Jul } & 2.62 & 2836.6 & 18.648 & 140.900 \\ \text { 1960 Oct } & 2.66 & 2800.2 & 18.700 & 140.833 \\ \text { 1961 Jan } & 2.69 & 2816.9 & 18.743 & 141.533 \\ \text { 1961 Apr } & 2.72 & 2869.6 & 18.785 & 142.567 \\ \text { 1961 Jul } & 2.84 & 2915.9 & 18.843 & 143.400 \\ \text { 1961 Oct } & 2.99 & 2975.3 & 18.908 & 144.700 \\ \text { 1962 Jan } & 3.50 & 3028.7 & 19.020 & 145.633 \\ \text { 1962 Apr } & 3.65 & 3062.1 & 19.047 & 146.600 \\ \text { 1962 Jul } & 3.66 & 3090.4 & 19.092 & 146.467 \\ \text { 1962 Oct } & 3.66 & 3097.9 & 19.152 & 147.267 \\ \text { 1963 Jan } & 3.66 & 3138.4 & 19.196 & 148.800 \\ \text { 1963 Apr } & 3.67 & 3177.7 & 19.233 & 150.167 \\ \text { 1963 Jul } & 3.75 & 3237.6 & 19.272 & 151.700 \\ \text { 1963 Oct } & 3.76 & 3262.2 & 19.418 & 153.167 \\ \text { 1964 Jan } & 3.76 & 3335.4 & 19.477 & 154.167 \\ \text { 1964 Apr } & 3.76 & 3373.7 & 19.529 & 155.233\end{array}$




\begin{tabular}{|c|c|c|c|c|}
\hline $1964 \mathrm{Jul}$ & 3.76 & 3419.5 & 19.607 & 157.767 \\
\hline 1964 Oct & 3.77 & 3429.0 & 19.703 & 159.833 \\
\hline 1965 Jan & 3.86 & 3513.3 & 19.801 & 161.033 \\
\hline 1965 Apr & 3.87 & 3560.9 & 19.887 & 161.967 \\
\hline $1965 \mathrm{Jul}$ & 3.88 & 3633.2 & 19.960 & 163.867 \\
\hline 1965 Oct & 3.96 & 3720.8 & 20.088 & 166.833 \\
\hline 1966 Jan & 3.97 & 3812.2 & 20.218 & 169.733 \\
\hline 1966 Apr & 3.97 & 3824.9 & 20.391 & 171.567 \\
\hline 1966 Jul & 3.97 & 3850.0 & 20.601 & 171.033 \\
\hline 1966 Oct & 3.97 & 3881.2 & 20.791 & 171.533 \\
\hline 1967 Jan & 3.97 & 3915.4 & 20.886 & 173.233 \\
\hline 1967 Apr & 3.97 & 3916.2 & 20.997 & 175.633 \\
\hline 1967 Jul & 3.97 & 3947.5 & 21.203 & 179.500 \\
\hline 1967 Oct & 3.97 & 3977.6 & 21.438 & 182.433 \\
\hline 1968 Jan & 3.97 & 4059.5 & 21.672 & 184.833 \\
\hline 1968 Apr & 3.98 & 4128.5 & 21.899 & 188.000 \\
\hline 1968 Jul & 3.99 & 4156.7 & 22.115 & 191.667 \\
\hline 1968 Oct & 4.00 & 4174.7 & 22.426 & 195.800 \\
\hline 1969 Jan & 4.00 & 4240.5 & 22.660 & 199.333 \\
\hline 1969 Apr & 4.01 & 4252.8 & 22.952 & 200.933 \\
\hline 1969 Jul & 4.01 & 4279.7 & 23.280 & 201.833 \\
\hline 1969 Oct & 4.02 & 4259.6 & 23.581 & 203.467 \\
\hline 1970 Jan & 4.24 & 4252.9 & 23.915 & 205.633 \\
\hline $1970 \mathrm{Apr}$ & 4.50 & 4260.7 & 24.247 & 207.167 \\
\hline $1970 \mathrm{Jul}$ & 4.52 & 4298.6 & 24.438 & 209.900 \\
\hline 1970 Oct & 4.52 & 4253.0 & 24.752 & 213.667 \\
\hline 1971 Jan & 4.50 & 4370.3 & 25.126 & 217.233 \\
\hline $1971 \mathrm{Apr}$ & 4.41 & 4395.1 & 25.455 & 221.833 \\
\hline $1971 \mathrm{Jul}$ & 4.42 & 4430.2 & 25.711 & 225.667 \\
\hline 1971 Oct & 4.47 & 4442.5 & 25.918 & 227.767 \\
\hline 1972 Jan & 4.45 & 4521.9 & 26.319 & 232.233 \\
\hline 1972 Apr & 4.39 & 4629.1 & 26.475 & 236.033 \\
\hline 1972 Jul & 4.40 & 4673.5 & 26.731 & 240.967 \\
\hline 1972 Oct & 4.41 & 4750.5 & 27.083 & 246.867 \\
\hline 1973 Jan & 4.44 & 4872.0 & 27.403 & 251.800 \\
\hline 1973 Apr & 4.52 & 4928.4 & 27.828 & 254.767 \\
\hline 1973 Jul & 4.77 & 4902.1 & 28.370 & 257.700 \\
\hline 1973 Oct & 4.88 & 4948.8 & 28.932 & 260.967 \\
\hline 1974 Jan & 4.89 & 4905.4 & 29.488 & 265.267 \\
\hline 1974 Apr & 4.91 & 4918.0 & 30.192 & 267.767 \\
\hline 1974 Jul & 4.93 & 4869.4 & 31.085 & 270.133 \\
\hline 1974 Oct & 4.95 & 4850.2 & 32.015 & 273.400 \\
\hline 1975 Jan & 4.95 & 4791.2 & 32.757 & 275.100 \\
\hline
\end{tabular}




\begin{tabular}{|c|c|c|c|c|}
\hline $1975 \mathrm{Apr}$ & 4.97 & 4827.8 & 33.245 & 279.267 \\
\hline $1975 \mathrm{Jul}$ & 5.00 & 4909.1 & 33.864 & 284.500 \\
\hline 1975 Oct & 5.01 & 4973.3 & 34.463 & 286.433 \\
\hline 1976 Jan & 5.01 & 5086.3 & 34.837 & 290.633 \\
\hline 1976 Apr & 5.00 & 5124.6 & 35.208 & 295.600 \\
\hline $1976 \mathrm{Jul}$ & 4.99 & 5149.7 & 35.686 & 298.600 \\
\hline 1976 Oct & 4.98 & 5187.1 & 36.331 & 303.933 \\
\hline 1977 Jan & 4.96 & 5247.3 & 36.943 & 311.233 \\
\hline 1977 Apr & 4.96 & 5351.6 & 37.470 & 317.333 \\
\hline 1977 Jul & 4.96 & 5447.3 & 37.927 & 322.333 \\
\hline 1977 Oct & 4.96 & 5446.1 & 38.758 & 328.633 \\
\hline 1978 Jan & 4.97 & 5464.7 & 39.326 & 335.567 \\
\hline $1978 \mathrm{Apr}$ & 4.98 & 5679.7 & 40.050 & 343.900 \\
\hline 1978 Jul & 4.99 & 5735.4 & 40.716 & 349.800 \\
\hline 1978 Oct & 4.99 & 5811.3 & 41.575 & 355.333 \\
\hline 1979 Jan & 4.99 & 5821.0 & 42.318 & 360.333 \\
\hline 1979 Apr & 5.01 & 5826.4 & 43.362 & 370.333 \\
\hline 1979 Jul & 5.26 & 5868.3 & 44.301 & 378.433 \\
\hline 1979 Oct & 5.59 & 5884.5 & 45.194 & 381.133 \\
\hline 1980 Jan & 5.92 & 5903.4 & 46.144 & 388.100 \\
\hline $1980 \mathrm{Apr}$ & 6.04 & 5782.4 & 47.178 & 385.900 \\
\hline $1980 \mathrm{Jul}$ & 5.49 & 5771.7 & 48.256 & 399.333 \\
\hline 1980 Oct & 6.08 & 5878.4 & 49.593 & 409.400 \\
\hline 1981 Jan & 6.60 & 6000.6 & 50.851 & 415.033 \\
\hline $1981 \mathrm{Apr}$ & 6.87 & 5952.7 & 51.813 & 425.767 \\
\hline 1981 Jul & 7.72 & 6025.0 & 52.730 & 426.933 \\
\hline 1981 Oct & 7.18 & 5950.0 & 53.692 & 432.133 \\
\hline 1982 Jan & 6.91 & 5852.3 & 54.421 & 442.433 \\
\hline $1982 \mathrm{Apr}$ & 7.17 & 5884.0 & 55.080 & 447.100 \\
\hline $1982 \mathrm{Jul}$ & 6.45 & 5861.4 & 55.864 & 452.100 \\
\hline 1982 Oct & 5.42 & 5866.0 & 56.470 & 470.267 \\
\hline 1983 Jan & 4.79 & 5938.9 & 56.929 & 484.033 \\
\hline $1983 \mathrm{Apr}$ & 5.65 & 6072.4 & 57.345 & 499.067 \\
\hline $1983 \mathrm{Jul}$ & 6.07 & 6192.2 & 57.929 & 510.367 \\
\hline 1983 Oct & 6.02 & 6320.2 & 58.355 & 519.200 \\
\hline 1984 Jan & 6.14 & 6442.8 & 59.096 & 528.000 \\
\hline 1984 Apr & 6.48 & 6554.0 & 59.602 & 537.300 \\
\hline 1984 Jul & 6.90 & 6617.7 & 60.081 & 541.667 \\
\hline 1984 Oct & 6.38 & 6671.6 & 60.465 & 547.600 \\
\hline 1985 Jan & 5.65 & 6734.5 & 61.136 & 562.400 \\
\hline $1985 \mathrm{Apr}$ & 5.38 & 6791.5 & 61.483 & 575.933 \\
\hline $1985 \mathrm{Jul}$ & 5.02 & 6897.6 & 61.736 & 596.200 \\
\hline 1985 Oct & 5.01 & 6950.0 & 62.140 & 613.267 \\
\hline
\end{tabular}




\begin{tabular}{lllll} 
1986 Jan & 4.88 & 7016.8 & 62.456 & 626.700 \\
1986 Apr & 4.44 & 7045.0 & 62.786 & 651.200 \\
1986 Jul & 3.99 & 7112.9 & 63.143 & 678.800 \\
1986 Oct & 3.72 & 7147.3 & 63.567 & 708.333 \\
1987 Jan & 3.62 & 7186.9 & 64.160 & 731.567 \\
1987 Apr & 3.69 & 7263.3 & 64.526 & 744.300 \\
1987 Jul & 3.80 & 7326.3 & 65.033 & 745.167 \\
1987 Oct & 3.99 & 7451.7 & 65.530 & 753.200 \\
1988 Jan & 3.89 & 7490.2 & 66.068 & 758.567 \\
1988 Apr & 3.88 & 7586.4 & 66.689 & 772.700 \\
1988 Jul & 4.15 & 7625.6 & 67.442 & 782.800 \\
1988 Oct & 4.40 & 7727.4 & 67.953 & 784.967 \\
1989 Jan & 4.79 & 7799.9 & 68.723 & 784.167 \\
1989 Apr & 5.14 & 7858.3 & 69.399 & 775.900 \\
1989 Jul & 5.02 & 7920.6 & 69.855 & 779.400 \\
1989 Oct & 4.91 & 7937.9 & 70.317 & 789.133 \\
1990 Jan & 4.73 & 8020.8 & 71.166 & 798.333 \\
1990 Apr & 4.72 & 8052.7 & 71.993 & 806.367 \\
1990 Jul & 4.69 & 8052.6 & 72.655 & 815.333 \\
1990 Oct & 4.62 & 7982.0 & 73.239 & 822.233 \\
1991 Jan & 4.15 & 7943.4 & 74.026 & 832.833 \\
1991 Apr & 3.76 & 7997.0 & 74.553 & 849.533 \\
1991 Jul & 3.57 & 8030.7 & 75.133 & 866.000 \\
1991 Oct & 3.21 & 8062.2 & 75.569 & 887.533 \\
1992 Jan & 2.66 & 8150.7 & 75.954 & 924.100 \\
1992 Apr & 2.47 & 8237.3 & 76.423 & 949.567 \\
1992 Jul & 2.19 & 8322.3 & 76.778 & 975.000 \\
1992 Oct & 2.04 & 8409.8 & 77.214 & 1014.767 \\
1993 Jan & 1.96 & 8425.3 & 77.677 & 1034.167 \\
1993 Apr & 1.89 & 8479.2 & 78.106 & 1062.900 \\
1993 Jul & 1.86 & 8523.8 & 78.466 & 1094.267 \\
1993 Oct & 1.85 & 8636.4 & 78.897 & 1122.300 \\
\hline 200 3. Bal & & & & \\
\hline
\end{tabular}

Source: FRED ret. May 6, 2013, Ball (2012)

Notes: r_star in \%, Y in billons of chained (2009) dollars, Py is the GDP deflator, M1 in billions of dollars

\section{References}

Baba, Y., Hendry, D. F., \& Starr, R. M. (1992). The demand for M1 in the U. S. A., 1960-1988, Review of Economic Studies, 95(1), 25-61. https://doi.org/10.2307/2297924

Ball, L. (2012). Short-Run Money Demand, Journal of Monetary Economics, 59, 622-633. https://doi.org/10.1016/j.jmoneco.2012.09.004

Calza, A., \& Zaghini, A. (2006). Non-linear dynamics in the euro-area demand for M1, ECB Working Paper Series, 592.

Davies, R. B. (1987). Hypothesis testing when a nuisance parameter is present only under the alternative, Biometrika, 64, 247-254. https://doi.org/10.1093/biomet/64.2.247

Dreger, Ch., \& Wolters, J. (2010). Investigating M3 money demand in the euro area, Journal of International Money and Finance, 29, 111-122. https://doi.org/10.1016/j.jimonfin.2009.02.002 
Duca, J. V. (2000). Financial technology shocks and the case of the missing M2, Journal of Money, Credit and Banking, 32(1), 820-839. https://doi.org/10.2307/2601185

Engsted, T., \& Johansen, S. (1997). Granger's Representation Theorem and Multicointegration, European University Institute, Economics Working Paper, 15.

Engsted, T., Gonzalo, J., \& Haldrup, N. (1997). Testing for multicointegration, Economics Letters, 56, 259-266. https://doi.org/10.1016/S0165-1765(97)00167-5

Ericsson, N. R., Hendry, D. F., \& Prestwich, K. M. (1998). The demand for broad money in the United Kingdom, 1878-1993, Scandinavian Journal of Economics, 100, 289-324. https://doi.org/10.1111/1467-9442.00103

Escribano, A. (2004). Nonlinear error correction: The case of money demand in the United Kingdom (1978-2000), Macroeconomic Dynamics, 8, 76-116. https://doi.org/10.1017/S1365100504030019

Fransens, Ph. H., \& van Oest, R. (2007). On the econometrics of the geometric lag model, Economics Letters, 95, 291-296. https://doi.org/10.1016/j.econlet.2006.10.023

Goldfeld, St. M. (1973). The demand for money revisited, Brookings Papers on Economic Activity, 2, 577-638. https://doi.org/10.2307/2534203

Granger, C. W. J., \& Lee, T. H. (1989). Investigation of production, sales and inventory relations using multicointegration and non-symmetric error correction models, Journal of Applied Econometrics, 4, 145-159. https://doi.org/10.1002/jae.3950040508

Hendry, D. F., \& Ericsson, N. R. (1991). An econometric analysis of the UK money demand in "Monetary trends in the United States and the United Kingdom" by Milton Friedman and Anna Schwartz, American Economic Review, 81, $8-38$.

Hoffman, D. L., \& Rasche, R. H. (1991). Long-run income and interest elasticities of money demand in the United States, Review of Economics and Statistics, 73(4), 665-674. https://doi.org/10.2307/2109405

Johansen, S. (2006). Statistical analysis of hypotheses on the cointegrating relations in the I(2) model, Journal of Econometrics, 132, 81-115. https://doi.org/10.1016/j.jeconom.2005.01.024

Koyck, L. M. (1954). Distributed Lags and Investment Analysis, North-Holland, Amsterdam.

Laidler, D. E. W. (1984). The "Buffer Stock" notion in monetary economics, Economic Journal supplement, 194, 17-34. https://doi.org/10.2307/2232652

Lee, T. H. (1992). Stock-flow relationships in housing construction, Oxford Bulletin of Economics and Statistics, 54, 419-430. https://doi.org/10.1111/j.1468-0084.1992.tb00010.x

Lütkepohl, H., Teräsvirta, T., \& Wolters, J. (1991). Investigating stability and linearity of a German M1 money demand function, Journal of Applied Econometrics, 14, 511-525. https://doi.org/10.1002/(SICI)1099-1255(199909/10)14:5\%3C511::AID-JAE529\%3E3.0.CO;2-C

Scheiblecker, M. (2013). Between cointegration and multicointegration - Modeling time series dynamics by cumulative error correction models, Economic Modelling, Elsevier, 31(C), 511-517. https://doi.org/10.1016/j.econmod.2012.11.042

Stock, J. H., \& Watson, M. W. (1993). A simple estimator of cointegrating vectors in higher order integrated systems, Econometrica, 61, 783-820. https://doi.org/10.2307/2951763

Teräsvirta, T., \& Eliasson, A. (2001). Non-linear error correction and the UK demand for broad money, 1878-1993, Journal of Applied Econometrics, 16, 277-288. https://doi.org/10.1002/jae.611

\section{Copyrights}

Copyright for this article is retained by the author(s), with first publication rights granted to the journal.

This is an open-access article distributed under the terms and conditions of the Creative Commons Attribution license which permits unrestricted use, distribution, and reproduction in any medium, provided the original work is properly cited. 